\title{
Analisa Pengaruh Variasi Beban Tekanan pada Friction Welding Terhadap Kekuatan Tarik Baja Karbon Sedang
}

\author{
Hasbi Assiddiq $\mathrm{S}^{1, \mathrm{a})}$, Asrul2,b), Muhammad Faisal ${ }^{3, \mathrm{c})}$, Jeffry Anggara ${ }^{4, \mathrm{~d})}$ \\ 1,2,3,4) Program Studi Teknik Mesin Politeknik Kotabaru, \\ Jl. Raya Stagen Km. 9,5 Stagen, Kotabaru-Kalimantan Selatan, Indonesia, 72114 \\ a) hasbiassiddiq999@gmail.com (corresponding author), b) mesinasrul@gmail.com, ${ }^{\mathrm{c}}$ faisal.thycal@gmail.com, \\ d)jeffryanggara64@gmail.com
}

\begin{abstract}
Abstrak
Proses penyambungan logam dengan metode pengelasan gesek (friction welding) merupakan salah satu jenis metode solid state proces yaitu proses pengelasan yang terjadi akibat adanya gesekan antara permukaan pada dua buah logam yang akan disambungkan. Gesekan yang terjadi akan menghasilkan panas yang dapat melumerkan kedua ujung logam hingga akhirnya akan menyatu. Adapun parameter penting dalam proses pengelasan gesek meliputi waktu gesekan (friction time), kecepatan putaran (rotational speed), beban tekanan gesek (friction pressure load), dan proses pengereman. Tujuan dari penelitian ini adalah; mengetahui pengaruh variasi beban tekan terhadap kekuatan tarik hasil pengelasan gesek menggunakan baja karbon sedang, dan mengetahui perubahan kekuatan tarik baja karbon sedang hasil pengelasan gesek. Penelitian ini menggunakan metode eksperimen perbandingan, yaitu suatu cara untuk membandingkan antara beberapa spesimen pada variasi beban tekan gesek terhadap kekuatan tarik. Hasil pengujian dan perhitungan memperlihatkan bahwa semakin besar beban yang diberikan pada saat proses las gesek maka semakin besar pula tegangan tarik bahan (baja karbon rendah). Tegangan tarik terendah sebesar 7,67 $\mathrm{kN} / \mathrm{mm}^{2}$ diperoleh pada saat beban tekanan gesek sebesar 39,23 $\mathrm{N}$. Tegangan tarik terbesar sebesar 10,46 $\mathrm{kN} / \mathrm{mm}^{2}$ diperoleh pada saat beban tekanan gesek sebesar 78,45 N.
\end{abstract}

Kata kunci: las gesek, baja karbon sedang, beban tekanan gesek, tegangan, regangan

\begin{abstract}
The metal joining process using the friction welding method is one type of solid state process method, namely the welding process that occurs due to friction between the surfaces of the two metals to be joined. The friction that occurs will produce heat that can melt the two ends of the metal until they are joined together. The important parameters in the friction welding process include friction time, rotation speed, friction pressure load, and the braking process. The aim of this research is; knowing the effect of variations in compressive loads on the tensile strength of the friction welding results using medium carbon steel, and knowing the changes in the tensile strength of medium carbon steel from the results of friction welding. This study uses a comparative experimental method, which is a way to compare between several specimens in the variation of frictional compressive loads to tensile strength. The test results and calculations show that the greater the load applied during the friction welding process, the greater the tensile stress of the material (low carbon steel). The lowest tensile stress of 7,67 kN/mm${ }^{2}$ is obtained when the frictional pressure load is 39,23 $\mathrm{N}$. The greatest tensile stress is $10,46 \mathrm{kN} / \mathrm{mm}^{2}$ is obtained when the frictional pressure load is $78,45 \mathrm{~N}$.
\end{abstract}

Keywords: friction welding, medium carbon steel, friction pressure load, stress, strain

\section{PENDAHULUAN}

Pengelasan merupakan penyambungan logam atau non logam dengan memanaskan bahan hingga temperatur leleh dengan atau tanpa tekanan, atau dengan tekanan sendiri, dengan atau tanpa menggunakan logam pengisi. Terdapat banyak jenis teknik pengelasan logam, salah satunya pengelasan gesek. Pengelasan gesek (friction welding) sering digunakan untuk penyambungan dua buah material yang sejenis atau berbeda jenis dan mempunyai sifat mekanik yang berbeda. Pengelasan gesek mempunyai keuntungan cocok untuk logam yang tidak sejenis, siklus waktunya pendek, kebanyakan disesuaikan dengan penampang lingkaran, kokoh dan secara biaya lebih murah. Seiring dengan perkembangan zaman, teknologi pengelasan telah mengalami perkembangan dengan pesat [1].

Pengelasan gesek merupakan salah satu metode dalam memecahkan permasalahan penyambungan logam yang sulit dilakukan. Pada pengelasan gesek proses penyambungan logamnya tanpa pencairan (solid state proces) yang mana proses pengelasan terjadi sebagai akibat penggabungan antara kecepatan putaran salah satu benda kerja yang berputar. Gesekan yang diakibatkan oleh pertemuan kedua benda kerja tersebut akan menghasilkan panas yang dapat melumerkan kedua ujung benda kerja yang bergesekan sehingga terjadi beberapa 
fenomena fisik seperti perubahan panas akibat gesekan deformasi plastis dan sebagainya. Adapun parameter penting dalam proses pengelasan gesek meliputi waktu gesekan (friction time), kecepatan putaran (rotational speed), beban tekanan gesek (friction pressure load), dan proses pengereman. Parameter-parameter yang ditunjukkan di atas akan berpengaruh terhadap sifat mekanik hasil sambungan las gesek, salah satu sifat mekanik yang penting dalam aplikasinya terutama pada hasil sambungan las gesek adalah kekuatan tarik [2].

Pengaruh durasi gesek tekanan gesek dan tekanan tempa terhadap kekuatan tarik las gesek pada material baja karbon sedang dimana didapatkan kekuatan tarik meningkat seiring dengan bertambahnya durasi gesek, tekanan gesek, dan tekanan tempa. Hal ini disebabkan tekanan gesek dan durasi gesekan yang dilakukan sudah mencapai temperatur tempa, sehingga tekanan tempa sebagai fungsi meningkatkan temperatur dan penyambungan diperoleh ikatan yang sangat baik [3].

Pada penelitian ini dilakukan analisis pengaruh variasi beban tekanan gesek $(39,23 N, 58,84 N$ dan 78,45 N) dengan putaran konstan $(1600 \mathrm{rpm})$ saat proses pengelasan gesek pada logam baja karbon sedang menggunakan waktu pengelasan 1 menit terhadap kekuatan tarik. Pengujian tarik dilakukan menggunakan mesin uji tarik dan proses pengelasan gesek menggunakan mesin bubut yang telah dimodifikasi pada kepala lepas (tail stock) untuk dapat melakukan penekanan gesek dengan menggunakan tali pada roda putar sehingga dapat diberikan beban.

\section{LANDASAN TEORI}

Baja adalah campuran dari besi dan karbon, dimana unsur karbon menjadi dasar campurannya. Penambahan atau pengurangan kadar karbon atau unsur paduan lain akan diperoleh kekuatan baja sesuai dengan yang diinginkan. Baja mempunyai unsru-unsur lain sebagai pemadu yang dapat mempengaruhi sifat dari baja. Penambahan unsur-unsur dalam baja karbon dengan satu unsur atau lebih, bergantung pada karakteristik baja karbon yang akan dibuat. Proses pembuatan dan sifatsifat alamiah dari bahan-bahan mentah yang digunakan, seluruh baja masih tetap mengandung bahan lain yang tidak murni dalam jumlah kecil yang meliputi posfor, belerang, mangan, dan silikon yang bercampur dengan elemen-elemen sisa lainnya. Kotoran tersebut tidak mungkin dapat dihilangkan seluruhnya dari logam [4].

Didalam proses uji tarik yang perlu periksa yaitu kelengkapan dan kesiapan mesin uji tarik, nyalakan software pembantu mesin uji tarik, setting software sesuai dengan data (material, dimensi spesimen) yang akan diukur, buka chuck mesin yang akan digunakan untuk menjepit spesimen, jepit spesimen dengan baik agar tidak terjadi slip yang dapat mempengaruhi hasil pengujian, setting cengkraman spesimen, pastikan software telah diatur dengan benar, nyalakan mesin uji tarik, Setelah spesimen putus, catat data pengujian yang ditunjukkan software, lalu lepas spesimen yang telah putus kemudian ganti dengan spesimen yang lain. Pada pengujian tarik diperoleh nilai-nilai dari gaya maksimum yaitu 4897,141
$N$, modulus young yaitu 973770513,171 Pa, tensile strength yaitu $128872129,645 P a$, kekuatan saat patah yaitu $128872129,645 P a$, elongasi maksimum yaitu $14,951 \%$, elongasi saat patah yaitu $14,951 \%$, maximum flexural strength yaitu $1726469,909 \mathrm{kPa}$, flexural modulus of elastisitas yaitu 122439832,152 $\mathrm{kPa}$ [5].

Penyambungan baja AISI 1040 batang silinder pejal dengan metode friction welding dapat dilakukan dengan cara direct drive welding. Perangkat yang digunakan yaitu mesin bubut Maro dengan daya $\mathrm{P}=5 P K$, putaran $\mathrm{n}$ $=1000 \mathrm{rpm}$, tekanan friction pf $70 \mathrm{Mpa}$, tekanan lanjut $\mathrm{Pa}=140 \mathrm{Mpa}$, dan koefisien gesek $\mu=0,8$ (dalam kondisi padat). Dari hasil pengujian tarik diperoleh kekuatan sambungan baja AISI 1040 yang disambungkan dengan metode friction welding yaitu kekuatan luluh $56,22 \mathrm{kgf} / \mathrm{mm}^{2}$, kekuatan tarik maksimum 57,40 $\mathrm{kgf} / \mathrm{mm}^{2}$ [6].

Pengaruh tekanan tempa terhadap struktur mikro dan sifat mekanik stainless steel SS 04 dengan metode friction welding. Kekuatan tertinggi terjadi pada proses operasional waktu gesek selama 35 detik, tekanan gesek sebesar $1226 \mathrm{kgf} / \mathrm{cm}^{2}$, panas yang ditimbulkan sebesar $892{ }^{\circ} \mathrm{C}$, putaran sebesar $4525 \mathrm{rpm}$, tekanan tempa sebesar $2453 \mathrm{kgf} / \mathrm{cm}^{2}$, nilai upset sebesar 3,2 $\mathrm{mm}$ akan menghasilkan kekuatan tarik paling tinggi yaitu 532,25 $\mathrm{N} / \mathrm{mm}^{2}$ [7].

Kekuatan tarik material AISI 1045 hasil pengelasan gesek dapat dilakukan, perangkat yang digunakan yaitu mesin bubut maximat V13 dengan putaran $2500 \mathrm{rpm}$. Dari data yang didapat spesimen durasi waktu 1 menit sebesar $72,31 \mathrm{kgf} / \mathrm{mm}^{2}$ adalah yang terbaik dihasilkan pada proses friction welding dengan putaran $2500 \mathrm{rpm}$. Karena nilai tegangan maksimum base material yaitu $70,18 \mathrm{kgf} / \mathrm{mm}^{2}$. Dari hasil pengujian tarik diperoleh kekuatan sambungan baja karbon sedang yang disambung dengan friction welding yaitu kekuatan luluh 52,1 $\mathrm{kgf} / \mathrm{mm}^{2}$, dan kekuatan tarik maksimal 72,31 $\mathrm{kgf} / \mathrm{mm}^{2}$. Dari hasil pengujian kekerasan yang tertinggi pada daerah sambungan terdapat pada variasi 1 menit yaitu sebesar 74,20 HRC, sedangkan nilai kekerasan terendah pada variasi waktu 2 menit yaitu sebesar 67,00 HRC. Hal ini disebabkan pengaruh waktu gesek pada saat proses pengelasan [3].

\section{A. Baja Karbon Sedang}

Baja karbon sedang adalah baja paduan yang mempunyai kadar karbon sama dengan baja lunak, namun didalamnya juga terdapat unsur-unsur paduan. Penambahan unsur tersebut dapat meningkatkan kekuatan baja tanpa mengurangi sifat keuletan, untuk spesifikasi jenis baja karbon rendah sesuai dengan kadar karbon diperlihatkan pada Tabel 1. Baja karbon adalah baja yang mengandung karbon mulai dari 0,1\% - 1,7\% [8].

Berdasarkan tingkat banyaknya kadar karbon, baja digolongkan menjadi tiga tingkatan:Baja karbon rendah yakni baja yang memiliki kandungan karbon kurang dari $0,30 \%$. Baja ini umumnya tersedia dalam bentuk pelat, profil, batangan untuk keperluan tempa, pekerjaan mesin. Jenis baja ini merupakan baja yang paling mudah diproduksi diantara karbon yang lain, mudah di 
machining dan dilas, serta keuletan dan ketangguhannya sangat tinggi tetapi kekerasannya rendah dan tahan aus. Baja karbon sedang adalah baja yang mengandung karbon antara 0,30\% - 0,60\%. Di dalam perdagangan biasanya digunakan sebagai alat-alat perkakas, baut, poros engkol, roda gigi, ragum, dan pegas. Baja karbon sedang memiliki kelebihan jika dibandingkan dengan baja karbon rendah yaitu kekerasannya lebih tinggi daripada baja karbon rendah, kekuatan tarik dan batas regang yang tinggi, tidak mudah dibentuk oleh mesin, lebih sulit dilakukan untuk pengelasan, dan dapat dikeraskan dengan baik. Baja karbon tinggi ialah baja yang memiliki kandungan karbon sebesar 0,60 \% - 1,7\%. Baja ini umumnya digunakan untuk keperluan peralatan konstruksi yang berhubungan dengan panas yang tinggi atau mengalami panas, misalnya landasan, palu, gergaji, pahat, kikir, bor, bantalan peluru, dan sebagainya $[8,9]$. Komposisi ditunjukkan pada Tabel 1.

Tabel 1. Komposisi Baja Karbon Sedang [10]

\begin{tabular}{cc}
\hline $\begin{array}{c}\text { Alloy (UNS } \\
\text { Designation) }\end{array}$ & \multicolumn{1}{c}{ Composition (wt \%) } \\
\hline \multicolumn{2}{c}{ Plain Carbon and Low-Alloy Steels } \\
A36 (ASTM A36) & $98.0 \mathrm{Fe}(\mathrm{min}), 0,29 \mathrm{C}, 1.0 \mathrm{Mn}$, \\
& $0,28 \mathrm{Si}$ \\
$1020(\mathrm{G} 10200)$ & $99.1 \mathrm{Fe}(\mathrm{min}), 0.20 \mathrm{C}, 0.45 \mathrm{Mn}$ \\
$1040(\mathrm{G} 10400)$ & $98.6 \mathrm{Fe}(\mathrm{min}), 0.40 \mathrm{C}, 0.75 \mathrm{Mn}$ \\
$4140(\mathrm{G} 41400)$ & $96.8 \mathrm{Fe}(\mathrm{min}), 0.40 \mathrm{C}, 0.90 \mathrm{Cr}$, \\
& $0.20 \mathrm{Mo}, 0.9 \mathrm{Mn}$ \\
$4340(\mathrm{G} 43400)$ & $95.2 \mathrm{Fe}(\mathrm{min}), 0.40 \mathrm{C}, 1.8 \mathrm{Ni}$, \\
& $0.80 \mathrm{Cr}, 0.25 \mathrm{Mo}, 0.7 \mathrm{Mn}$ \\
\hline
\end{tabular}

Baja ini mengandung karbon antara 0,30\% - 0,60\%. Didalam perdagangan biasanya dipakai sebagai alat-alat perkakas, baut, poros engkol, roda gigi, ragum, pegas dan lain-lain. Baja karbon menengah bersifat lebih kuat daripada baja karbon rendah sehingga lebih sulit dipotong, dibengkokkan, atau dilas. Baja karbon menengah yang berkadar 0,3-0,4 persen digunakan sebagai batang penghubung, pin engkol, dan as roda. Sedangkan baja karbon menengah dengan kadar 0,4-0,5 persen digunakan sebagai bahan pembuatan as roda mobil, poros engkol, rel, boiler, dan obeng. Serta baja karbon menengah sekitar 0,5-0,6 persen merupakan bahan baku palu dan kereta luncur [9].

\section{B. Pengelasan Gesek (Friction Welding)}

Pada tahun 1950, Al Chudikov seorang ahli mesin dari Uni Sovyet, mengemukakan hasil penelitiannya tentang teori tenaga mekanik dapat diubah menjadi energi panas. Gesekan yang terjadi pada bagian-bagian mesin yang bergerak menimbulkan banyak kerugian karena sebagian tenaga mekanik yang dihasilkan berubah menjadi panas. Chudikov berpendapat bahwa proses demikian harusnya dapat digunakan pada proses pengelasan. Setelah melalui percobaan dan penelitian dia berhasil mengelas dengan memanfaatkan panas yang terjadi akibat gesekan. Pengelasan gesek salah satu solusi dalam proses penyambungan logam yang sulit dilakukan dengan pengelasan cair (fusion welding). Proses penyambungan logam dengan metode ini tanpa pencairan (solid state) dimana proses pengelasan terjasi sebagai akibat penggabungan antara kecepatan putaran salah satu benda kerja yang menimbulkan gesekan. Gesekan yang diakibatkan oleh kedua permukaan benda kerja tersebut menghasilkan panas yang dapat melumerkan kedua ujung benda kerja dan pada akhirnya terjadi proses penyambungan [3].

Produk yang dapat dilas menggunakan las gesek yaitu gardan mobil Gambar 1 [1].



Gambar 1. Hasil Pengelasan Gesek pada Gardan Mobil

Beberapa keuntungan dari pengelasan gesek ini adalah penghematan logam pengisi dan waktu untuk penyambungan dua material yang sama maupun berbeda. Sedangkan parameter proses yang penting adalah waktu gesekan, tekanan gesekan, waktu tempa, tekanan tempa dan kecepatan putar. Pada proses penyambungan ini terjadi proses deformasi plastis akibat tekanan tempa dan terjadi proses diffusi karena adanya panas yang tinggi sehingga menghasilkan sambungan yang berkualitas tinggi antara bahan serupa maupun berbeda [7].

Namun dibalik keunggulan tesebut terdapat juga beberapa keterbatasan yakni benda yang disambung harus simetris, permukaan pelat/datar dan bentuk batang bulat serta harus ada salah satu dari material yang disambung memiliki sifat mampu dideformasi secara plastis [6].

Tahapan proses pengelasan gesek diilustrasikan dalam bentuk gambar yang derlihatkan pada Gambar 2 [3].

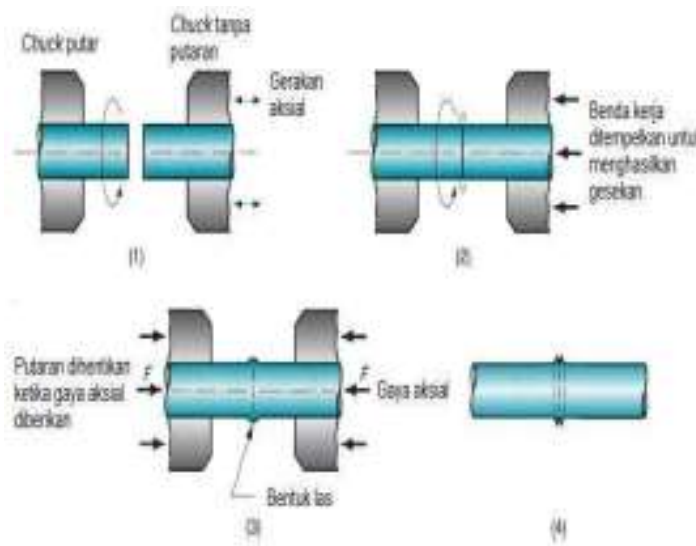

Gambar 2. Proses Pengelasan Gesek 
Daerah pengelasan terdiri dari tiga bagian yaitu; daerah logam las, daerah pengaruh panas atau heat affected zone disingkat menjadi HAZ dan logam induk yang tidak mendapatkan pengaruh panas proses pengelasan seperti yang diperlihatkan pada Gambar 3 [11].



Gambar 3. Daerah Pengelasan

1. Daerah logam las yaitu bagian dari logam yang pada waktu pengelasan mencair kemudian kembali membeku/mengeras.

2. Heat Affected Zone (HAZ) adalah logam dasar yang bersebelahan dengan logam las yang selama proses pengelasan mengalami siklus termal pemanasan dan pendinginan cepat sehingga daerah ini umumnya yang paling kritis dari sambungan.

3. Logam induk adalah bagian dasar dimana panas dan suhu pengelasan tidak menyebabkan terjadinya perubahan-perubahan struktur dan sifat.

Pengelasan yang dilakukan dengan las gesek langsung terdapat tahap pengelasan yang semua variabelnya mempengaruhi satu sama lain. Karena sifatnya saling mempengaruhi maka las gesek langsung ini tidak boleh dilaksanakan dengan sembarangan sehingga bisa menyebabkan penurunan sambungan lasan, untuk itu dilakukan proses pengelasan gesek langsung agar bisa mengetahui variabel yang mempengaruhi kualitas hasil sambungan tanpa menggunakan filler sehingga cara pengelasan ini dirasa lebih efisien dan dapat meningkatkan kekuatan sambungan las [2].

\section{Pengujian Tarik}

Pengujian tarik yaitu pengujian yang bertujuan untuk mendapatkan gambaran tentang sifat-sifat dan keadaan dari suatu logam. Pengujian tarik dilakukan dengan penambahan beban secara perlahan-lahan, kemudian akan terjadi pertambahan panjang yang sebanding dengan gaya yang bekerja. Kesebandingan ini terus berlanjut sampai bahan sampai titik propotionality limit. Setelah itu pertambahan panjang yang terjadi sebagai akibat penambahan beban tidak lagi berbanding lurus, pertambahan beban yang sama akan menghasilkan penambahan panjang yang lebih besar dan suatu saat terjadi penambahan panjang tanpa ada penambahan beban, batang uji bertambah panjang dengan sendirinya. Hal ini dikatakan batang uji mengalami yield (luluh). Keadaan ini hanya berlangsung sesaat dan setelah itu akan naik lagi [5].

Uji tarik adalah salah satu uji stress-strain mekanik yang bertujuan untuk mengetahui kekuatan bahan terhadap gaya tarik. Dalam pengujiannya, bahan uji ditarik sampai putus. Banyak hal yang dapat kita pelajari dari hasil uji tarik. Biasanya yang menjadi fokus perhatian adalah kemampuan maksimum bahan tersebut dalam menahan beban tarik [12].

Pengujian tarik yaitu pengujian yang bertujuan untuk mendapatkan gamabran tentang sifat-sifat dan keadaan dari suatu logam. Pengujian tarik dilakukan dengan penambahan beban secara perlahan, kemudian akan terjadi pertambahan panjang yang sebanding dengan gaya yang bekerja. Kesebandingan ini terus berlanjut sampai bahan sampai titik propotionality limit. Setelah itu pertambahan panjang yang terjadi sebagai akibat penambahan beban tidak lagi berbanding lurus, pertambahan beban yang sama akan menghasilkan penambahan panjang yang lebih besar dan suatu saat terjadi penambahan panjang tanpa ada penambahan beban, batang uji bertambah panjang dengan sendirinya. Hal ini dikatakan batang uji mengalami yield (luluh). Keadaan ini hanya berlangsung sesaat dan setelah itu akan naik lagi. Kenaikan beban ini akan berlangsung sampai mencapai maksimum, untuk batang yang ulet beban mesin tarik akan turun lagi sampai akhirnya putus. Pada saat beban mencapai maksimum, batang uji mengalami pengecilan penampang setempat (local necting) dan penambahan panjang terjadi hanya disekitar necking tersebut. Pada batang getas tidak terjadi necking dan batang akan putus pada saat beban maksimum. Ilustrasi spesimen uji tarik dari awal sampai akhir pengujian tarik diperlihatkan pada Gambar 4 [5].
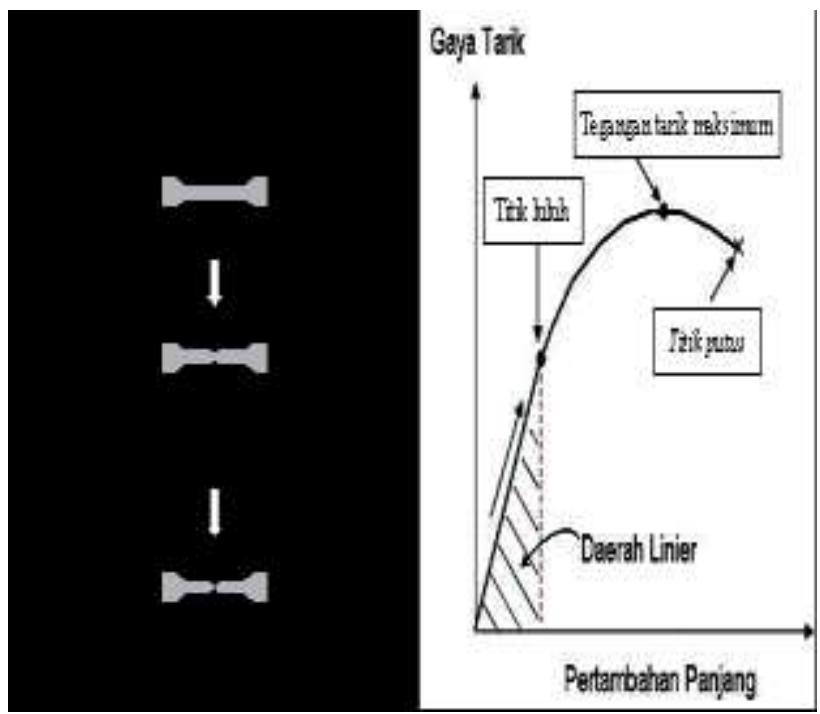

Gambar 4. Spesimen dan Grafik Uji Tarik 
Bila suatu bahan/material terus ditarik sampai putus, maka akan diperoleh profil tarikan yang lengkap berupa kurva seperti yang diperlihatkan pada Gambar 4. Kurva tersebut menunjukkan hubungan antara gaya tarikan dengan perubahan panjang. Profil ini sangat dibutuhkan dalam menentukan bahan/material yang akan digunakan pada suatu konstruksi logam [13].

Hubungan antara beban atau gaya yang diberikan berbanding lurus dengan perubahan panjang bahan tersebut atau daerah linier (linear zone). Pada daerah tersebut kurva pertambahan panjang terhadap beban berdasarkan hukum Hooke yaitu perbandingan antara tegangan (stress) dan regangan (strain) adalah konstan. Stress adalah beban dibagi luas penampang bahan dan strain adalah pertambahan panjang dibagi panjang awal bahan $[13,14]$.

Stress [14]

$$
\begin{array}{r}
\sigma=\frac{F}{A} \\
\text { Strain [14] } \\
\varepsilon=\frac{\Delta L}{L}
\end{array}
$$

Hubungan antara stress dan strain

$$
\begin{aligned}
& E=\frac{\sigma}{\varepsilon} \\
& \text { Dimana: } \\
& \sigma \quad=\text { tegangan }\left(\mathrm{kN} / \mathrm{mm}^{2}\right) \\
& \mathrm{F}=\text { gaya tarik }(\mathrm{kN}) \\
& \mathrm{A}=\text { luas penampang }\left(\mathrm{mm}^{2}\right) \\
& \varepsilon=\text { regangan } \\
& \Delta \mathrm{L}=\text { pertambahan panjang }(\mathrm{mm}) \\
& \mathrm{L}=\text { panjang awal }(\mathrm{mm}) \\
& \mathrm{E}=\text { modulus elastis }(\mathrm{Pa})
\end{aligned}
$$

Pembebanan tarik dilaksanakan dengan mesin pengujian tarik yang selama pengujian akan mencatat setiap kondisi bahan sampai terjadinya tegangan ultimate, juga sekaligus akan menggambarkan diagram tarik benda uji, adapun panjang L $f$ akan diketahui setelah benda uji patah dengan mengunakan pengukuran secara normal tegangan ultimate adalah tegangan tertinggi yang bekerja pada luas penampang semula. Diagram yang diperoleh dari uji tarik pada umumnya di gambarkan sebagai diagram tegangan regangan [15]. Uji tarik merupakan suatu metode yang digunakan untuk menguji kekuatan suatau bahan/metiral dengan memberikan beban gaya yang arahnya berlawanan. Sifat mekanis logam yang dapat diketahui setelah proses pengujian seperti kekuatan tarik, keuletan dan ketangguhan [14].

Banyak hal yang dapat dipelajari dari hasil uji tarik. Biasanya yang menjadi fokus perhatian adalah kemampuan maksimum bahan tersebut dalam menahan beban tarik. Kemampuan ini umumnya disebut (ultimate tensile strength) dalam bahasa Indonesia disebut kekuatan tarik maksimum. Perubahan panjang dalam kurva disebut sebagai regangan yang didefinisikan sebagai perubahan panjang yang terjadi akibat perubahan statik $(\Delta \mathrm{L})$ terhadap panjang batang mula-mula $\left(L_{o}\right)$.
Tegangan yang dihasilkan pada proses ini disebut dengan tegangan teknik $(\sigma)$, dimana didefinisikan sebagai nilai pembebanan yang terjadi $(\mathrm{F})$ pada suatu luas penampang awal $\left(A_{o}\right)$ [12]. Pengujian tarik pada umumnya menghasilkan parameter kekuatan tarik (ultimate strength) maupun luluh (yield strength). Keuletan bahan biasanya disajikan dalam bentuk persentase perpanjangan dan kontraksi/ reduksi penampang (reduction of area). Ini adalah kurva standar ketika melakukan eksperimen uji tarik dimana perbandingan tegangan $(\sigma)$ dan regangan $(\varepsilon)$ selalu tetap, kurva yang menyatakan hubungan antara strain dan stress seperti ini disingkat kurva SS (SS curve) [14]

\section{METODE PENELITIAN}

Metode penelitian merupakan suatu cara yang digunakan dalam penelitian, sehingga dalam proses pelaksanaannya teratur serta diperolehnya hasil sesuai dengan tujuan dari penelitian yang akan dilaksanakan. Dalam penelitian yang telah dilaksanakan ini peneliti menggunakan metode eksperimen perbandingan yaitu membandingkan antara spesimen dengan beban tekanan gesek 39,23 $N$, 58,84 $N$ dan 78,45 $N$ dimana yang diamati adalah kekuatan tariknya dari hasil pengujian tarik yang dilakukan. Penelitian ini dilaksanakan dengan terlebih dahulu melakukan persiapan bahan dan peralatan yang diperlukan dalam proses pengelasan gesek sampai dengan pengujian tarik seperti yang diperlihatkan pada Gambar 5 .

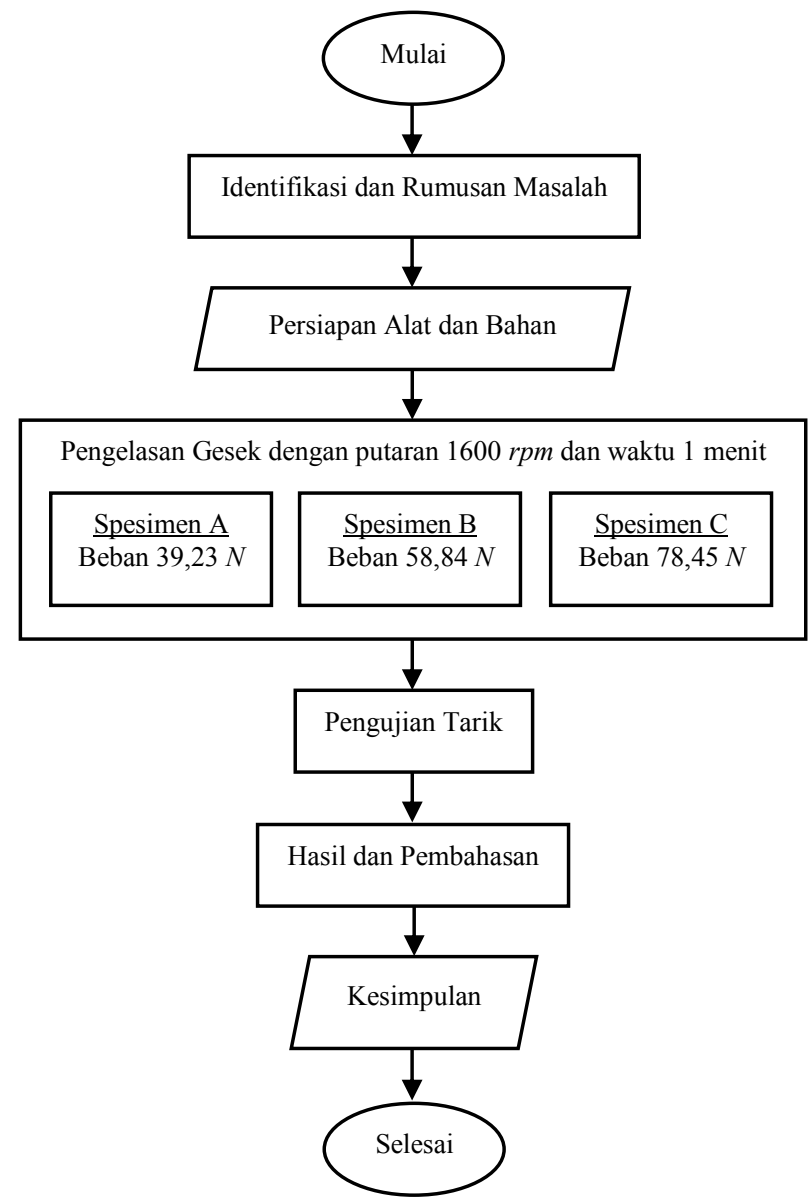

Gambar 5. Diagram Alir Penelitian 
Spesimen uji tarik yang akan digunakan yaitu standar JIS Z2201 No. 14A seperti yang diperlihatkan pada Gambar 6 [15].

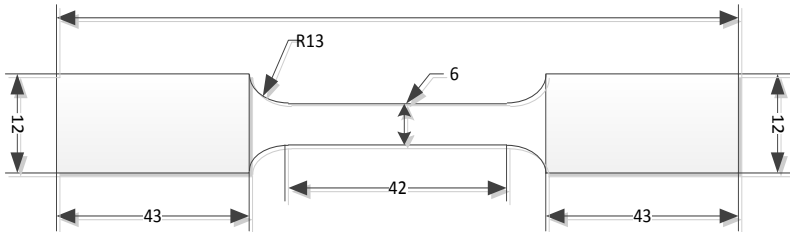

Gambar 6. Standar JIS Z2201 No. 14A

Pelaksanaan penelitian ini dilakukan di dua tempat yaitu Workshop Politeknik Kotabaru, Kalimantan Selatan sebagai tempat melakukan pengelasan gesek dan pembentukan spesimen menggunakan mesin bubut, sedangkan untuk pengujian tarik dilakukan di BLKI (Balai Latihan Kerja Industri) Makassar, Sulawesi Selatan.

Proses pengelasan gesek dengan mesin bubut yang sudah di modifikasi diperlihatkan pada Gambar 7 bentuk sketsa pada proses pengelasan gesek.

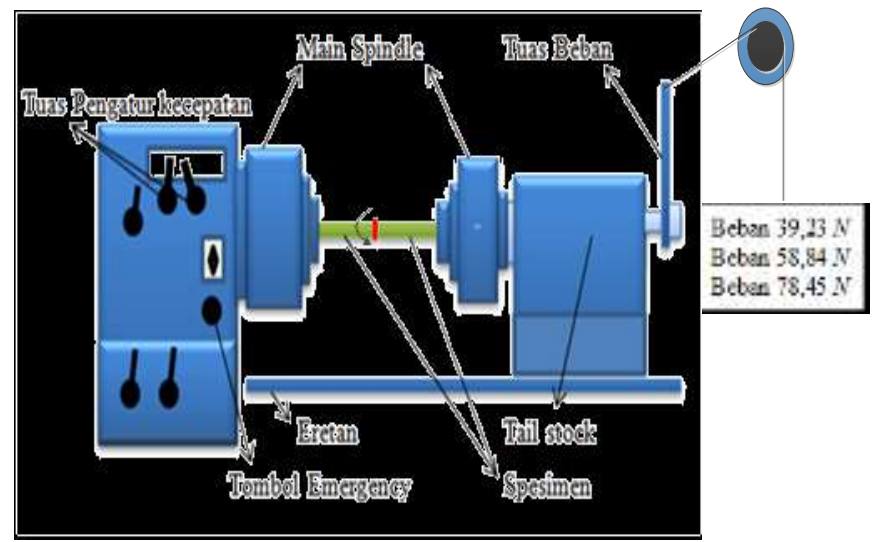

Gambar 7. Sketsa Pengelasan Gesek

Adapun langkah pengelasan gesek pertama material poros yang akan dilas, diperlihatkan pada Gambar 8 . material dijepit pada chuck bubut yang berputar dan material lainnya dijepit pada chuck yang terpasang pada tail stock.



Gambar 8. Pemasangan Spesimen pada Chuck Bubut

Selanjutnya mengatur tuas kecepatan putaran mesin bubut pada $1600 \mathrm{rpm}$. Sebelum menghidupkan mesin, beban tekanan gesek diberikan terlebih dahulu sesuai dengan yang diinginkan diperlihatkan pada Gambar 9 beban tekanan tersebut ditempatkan pada roda putar yang sudah dimodifikasi untuk menciptakan panas yang diakibatkan oleh gesekan antara kedua permukaan. Variasi beban tekanan gesek yang diberikan adalah 39,23 $N, 58,84 N$ dan $78,45 N$.

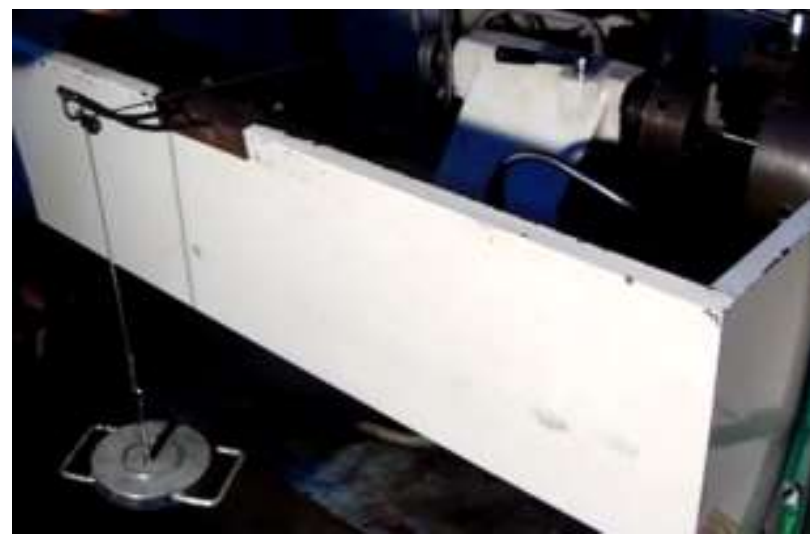

Gambar 9. Beban Tekanan Gesek

Langkah selanjutnya yaitu proses pengelasan gesek yang diperlihatkan pada Gambar 10 (a) awal mesin hidup pada kecepatan 1600 rpm, Gambar 10 (b) menunjukan pelumeran pada material poros, Gambar 10 (c) ketika material telah tersambung, proses pengereman dilakukan mendadak setelah mesin dimatikan. dan proses pengelasan gesek selesai. 


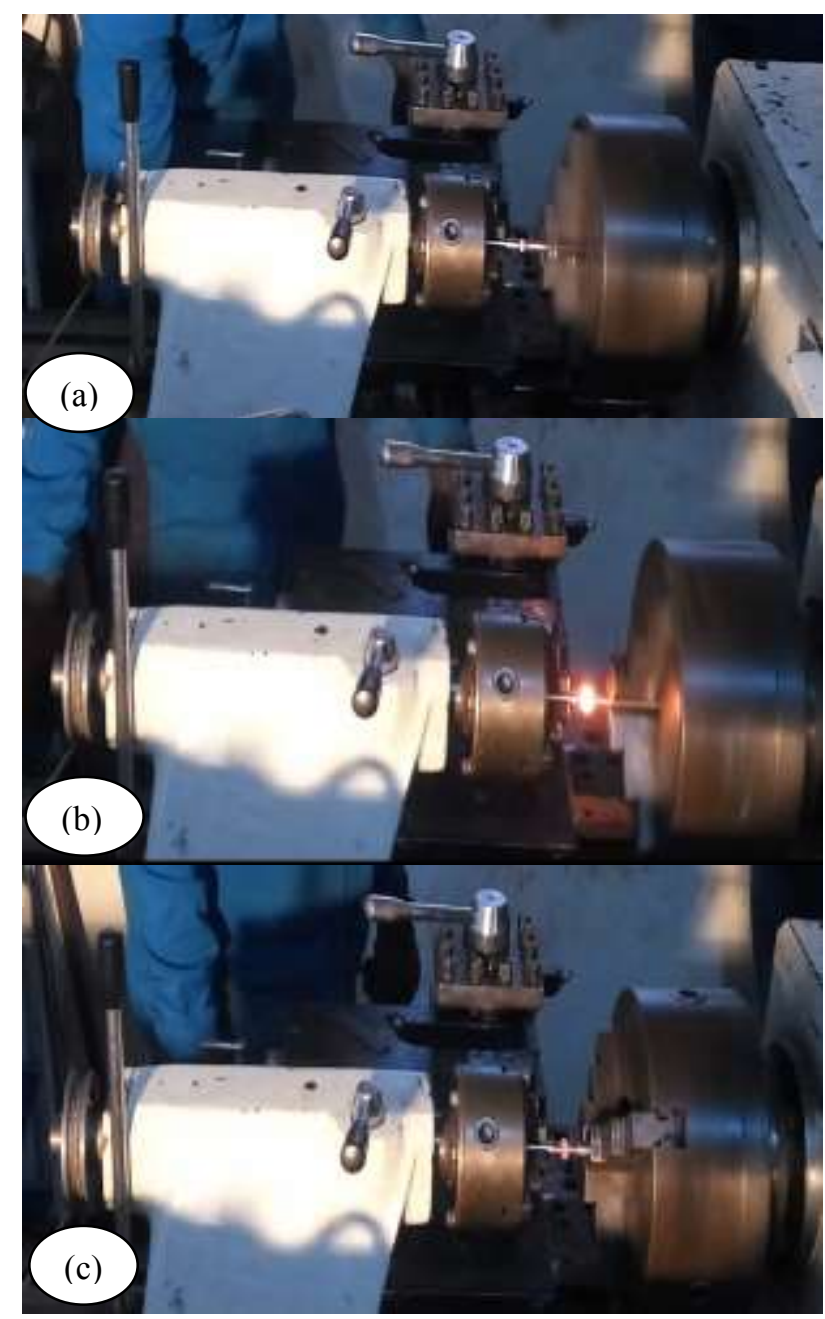

Gambar 10. Proses Pengelasan Gesek

\section{HASIL DAN PEMBAHASAN}

\section{A. Hasil Pengelasan Gesek}

Proses pengelasan gesek dilakukan menggunakan mesin bubut pada kecepatan putaran $1600 \mathrm{rpm}$ dan waktu masing-masing 1 menit sebanyak tiga kali dengan memberikan variasi beban tekanan gesek mulai 39,23 $\mathrm{N}$, $58,84 N$ dan 78,45 $N$ menghasilkan spesimen yang akan dibentuk sesuai dengan standar, adapun spesimen hasil pengelasan gesek ditunjukkan pada Gambar 11 .

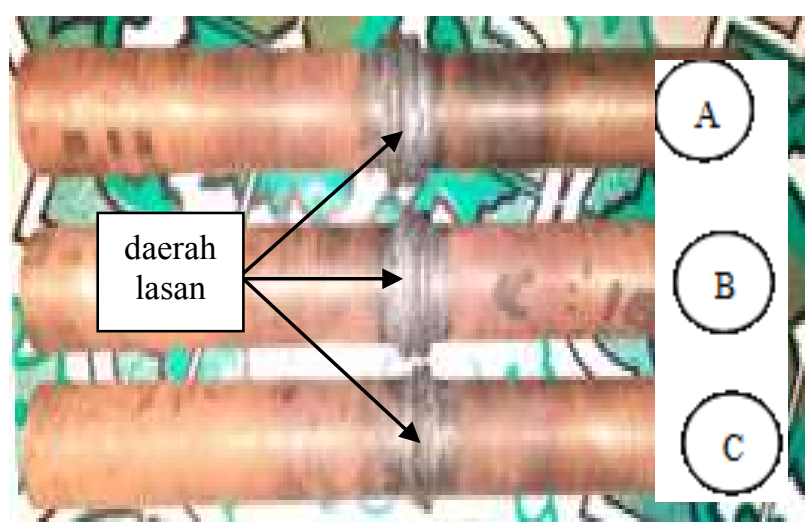

Gambar 11. Hasil Pengelasan Gesek
Dalam proses pengelasan gesek yang dilaksanakan ditemukan beberapa hal yang harus menjadi perhatian khususnya pada saat material sudah melumer dan waktu pengelesan telah tercapai maka putaran harus dihentikan sepenuhnya agar sambungan las yang diperoleh lebih baik.

Setelah proses pengelasan gesek selesai dilakukan terhadap material tersebut di atas, maka selanjutnya dilakukan pembentukan spesimen uji tarik menggunakan mesin bubut dengan ukuran sesuai dengan standar yang telah ditentukan sebelumnya yaitu JIS Z2201 No. 14A seperti yang diperlihatkan pada Gambar 12 .

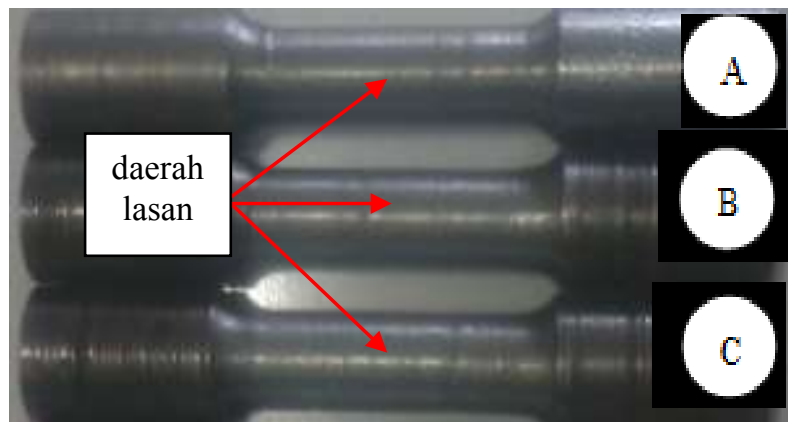

Gambar 12. Spesimen Uji Tarik Setelah Dibentuk

Pembentukan spesimen uji sesuai standar yang diinginkan harus dilakukan dengan baik agar spesimen uji tariknya semua memiliki dimensi yang sama karena spesimennya harus memenuhi standar JIS Z2201 No. 4A sehingga hasilnya dapat dibandingkan setelah dilakukan proses pengujian tarik terhadap semua spesimen tersebut.

\section{B. Hasil Pengujian Tarik}

Pada pengujian tarik yang telah dilakukan terhadap ketiga spesimen uji diperoleh hasil yang menunjukkan bahwa semakin besar beban tekanan gesek yang diberikan pada saat proses pengelasan gesek maka kekuatan sambungan bahan/material akan semakin baik. Adapun hasil pengujian yang diperoleh terhadap spesimen dengan beban pengelasan 39,23 $N$ diperlihatkan pada Tabel 2 dan Gambar 13.

Tabel 2. Hasil tarik sampel beban 39,23 N

\begin{tabular}{cccc}
\hline Sampel ID & $\begin{array}{c}\text { Beban } \\
\text { Tekanan }\end{array}$ & Test Date & $\mathbf{2 1 / 7 / 2 0 2 0}$ \\
\hline Operator & $\mathbf{3 9 , 2 3 ~} \mathrm{N}$ & Type & Circle \\
\hline Size $(m m)$ & 14 & $\mathrm{Ao}\left(\mathrm{mm}^{s}\right)$ & 153,94 \\
Lo $(\mathrm{mm})$ & 60 & $\mathrm{Lu}(\mathrm{mm})$ & \\
$\mathrm{A}(\%)$ & $/$ & $\mathrm{Au}\left(\mathrm{mm}^{2}\right)$ & \\
$\mathrm{Z}(\%)$ & $/$ & $\mathrm{Fm}(k N)$ & 43,05 \\
$\mathrm{Rm}(M P a)$ & 280 & $\mathrm{FeH}(k N)$ & $/$ \\
$\mathrm{UYS}(M P a)$ & $/$ & $\mathrm{FeL}(k N)$ & $/$ \\
$\mathrm{LYS}(M P a)$ & $/$ & $\mathrm{Fp}(k N)$ & 41,10 \\
$\operatorname{Rp}(M P a)$ & 265 & $\mathrm{Ft}(k N)$ & 1,35 \\
$\operatorname{Rt}(M P a)$ & 10 & $\mathrm{E}(G P a)$ & 3,33 \\
\hline
\end{tabular}




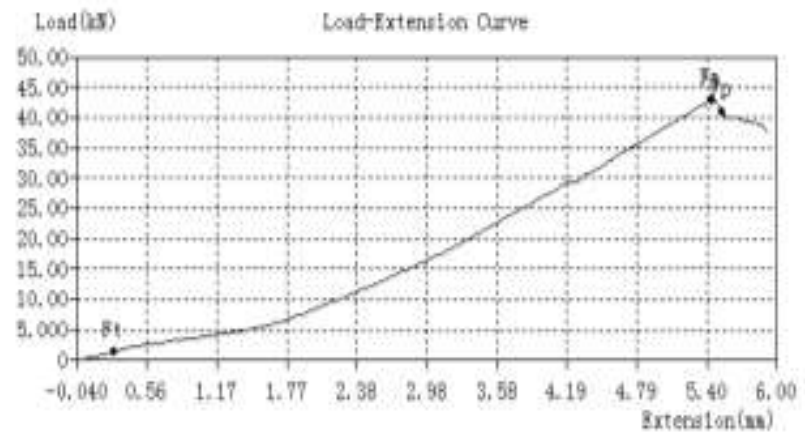

Gambar 13. Hasil Pengujian Tarik pada Sampel (Beban $39,23 N)$

Untuk spesimen pengelasan gesek dengan beban 39,23 $N$ dilakukan uji tarik diperoleh hasil seperti yang diperlihatkan pada Tabel 2 dan Gambar 13, dimana beban tarik maksimum yang diperoleh yaitu $43,05 \mathrm{kN}$.

Pengujian tarik berikutnya dilakukan terhadap spesimen dengan beban tekanan gesek 58,84 N ditunjukkan pada Tabel 3 dan Gambar 14.

Tabel 3. Hasil tarik sampel beban 58,84 $N$

\begin{tabular}{|c|c|c|c|}
\hline Sampel ID & $\begin{array}{c}\text { Beban } \\
\text { Tekanan }\end{array}$ & Test Date & $21 / 7 / 2020$ \\
\hline Operator & $58,84 N$ & Type & Circle \\
\hline Size $(\mathrm{mm})$ & 14 & Ao $\left(m m^{s}\right)$ & 153,94 \\
\hline Lo $(m m)$ & 60 & $\mathrm{Lu}(m m)$ & \\
\hline $\mathrm{A}(\%)$ & / & $\mathrm{Au}\left(m m^{2}\right)$ & \\
\hline$Z(\%)$ & / & $\operatorname{Fm}(k N)$ & 45,10 \\
\hline $\mathrm{Rm}(M P a)$ & 295 & $\mathrm{FeH}(k N)$ & 1 \\
\hline UYS $(M P a)$ & / & $\mathrm{FeL}(k N)$ & / \\
\hline LYS $(M P a)$ & / & $\mathrm{Fp}(k N)$ & 45,10 \\
\hline $\operatorname{Rp}(M P a)$ & 295 & $\mathrm{Ft}(k N)$ & 1,15 \\
\hline $\operatorname{Rt}(M P a)$ & 5 & $\mathrm{E}(G P a)$ & 3,10 \\
\hline
\end{tabular}

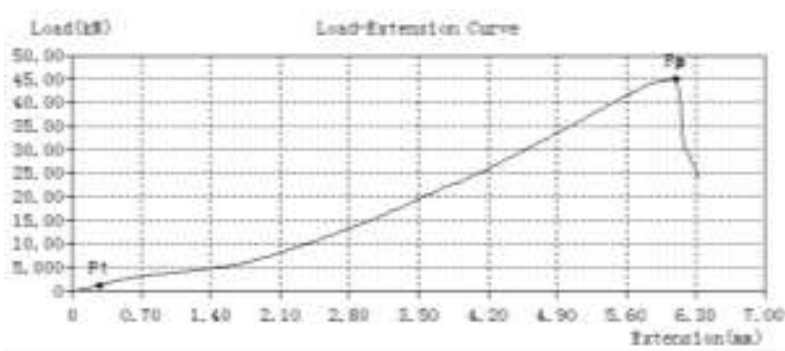

Gambar 14. Hasil Pengujian Tarik pada Sampel (Beban $58,84 N)$

Hasil pengujian tarik yang kedua dilakukan terhadap spesimen pengelasan gesek dengan beban tekanan gesek $58,84 N$ diperoleh hasil yang ditunjukkan pada Tabel 3 dan Gambar 14, dimana beban tarik maksimum yang diperoleh 45,10 $k N$ lebih besar dibandingkan dengan spesimen beban tekanan gesek 39,23 N.

Pengujian tarik yang terakhir dilakukan terhadap spesimen dengan beban tekanan gesek 78,45 N ditampilkan pada Tabel 4 dan Gambar 15.
Tabel 4. Hasil tarik sampel beban 78,45 N

\begin{tabular}{cccc}
\hline Sampel ID & $\begin{array}{c}\text { Beban } \\
\text { Tekanan }\end{array}$ & Test Date & $\mathbf{2 1 / 7 / 2 0 2 0}$ \\
\hline Operator & $\mathbf{7 8 , 4 5 ~} \boldsymbol{N}$ & Type & Circle \\
\hline Size $(m m)$ & 14 & Ao $\left(\mathrm{mm}^{s}\right)$ & 153,94 \\
Lo $(m m)$ & 60 & $\mathrm{Lu}\left(\mathrm{mm}^{2}\right)$ & \\
$\mathrm{A}(\%)$ & $/$ & $\mathrm{Au}\left(\mathrm{mm}^{2}\right)$ & \\
$\mathrm{Z}(\%)$ & $/$ & $\mathrm{Fm}(k N)$ & 54,45 \\
$\mathrm{Rm}(M P a)$ & 355 & $\mathrm{FeH}(k N)$ & $/$ \\
$\mathrm{UYS}(M P a)$ & $/$ & $\mathrm{FeL}(k N)$ & $/$ \\
$\mathrm{LYS}(M P a)$ & $/$ & $\mathrm{Fp}(k N)$ & 53,25 \\
$\operatorname{Rp}(M P a)$ & 345 & $\mathrm{Ft}(k N)$ & 1,05 \\
$\operatorname{Rt}(M P a)$ & 5 & $\mathrm{E}(G P a)$ & 3,47 \\
\hline
\end{tabular}

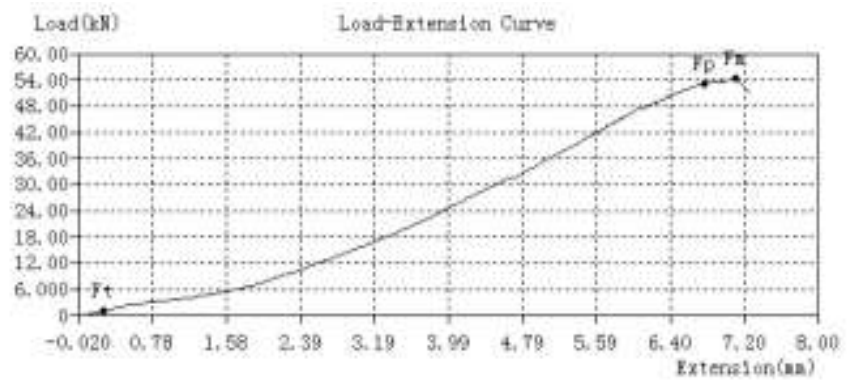

Gambar 15. Hasil pengujian tarik pada sampel (beban $78,45 N$

Hasil pengujian tarik yang terakhir dilakukan terhadap spesimen pengelasan gesek dengan beban 78,45 N diperoleh hasil yang diperlihatkan pada Tabel 4 dan Gambar 15, dimana beban tarik maksimum yang diperoleh lebih besar dibandingkan dengan kedua spesimen lainnya baik yang menggunakan beban pengelasan $39,23 N$ maupun $58,84 N$ dimana hasilnya adalah $54,45 \mathrm{kN}$.

Dari hasil pengujian tarik yang telah dilakukan terhadap ketiga spesimen tersebut di atas kemudian datanya dianalisis dengan terlebih dahulu melakukan perhitungan menggunakan persamaan pada bagian sebelumnya di atas agar dapat diketahui pengaruh dari variasi beban tekanan gesek yang diberikan pada saat proses pengelasan gesek serta perbandingan kekuatan dari ketiga spesimen yang telah melalui proses pengelasan gesek dan pengujian tarik.

\section{Hasil Analisis Data dan Pembahasan}

Adapun data hasil perhitungan terhadap data yang diperoleh dari pengujian tarik diperlihatkan pada Tabel 5 dimana gaya tarik terbesar diperoleh pada spesimen yang diberikan beban tekanan gesek 78,45 $N$ saat proses pengelasan gesek. 
Tabel 5. Hasil Perhitungan Data Uji Tarik

\begin{tabular}{cccc}
\hline \multirow{2}{*}{ Parameter } & \multicolumn{3}{c}{ Sampel dengan Beban } \\
\cline { 2 - 4 } & $\mathbf{3 9 , 2 3 ~} \boldsymbol{N}$ & $\mathbf{5 8 , 8 4} \boldsymbol{N}$ & $\mathbf{7 8 , 4 5 ~ N}$ \\
\hline Do $(\mathrm{mm})$ & 14 & 14 & 14 \\
$\mathrm{D}_{1}(\mathrm{~mm})$ & 13,5 & 13 & 13 \\
Lo $(\mathrm{mm})$ & 60 & 60 & 60 \\
$\mathrm{~L}_{1}(\mathrm{~mm})$ & 73 & 73 & 73 \\
Beban $(\mathrm{kgf})$ & 4389,89 & 4598,93 & 5552,37 \\
Ao $\left(\mathrm{mm}^{2}\right)$ & 615,44 & 615,44 & 615,44 \\
$\mathrm{~A}_{1}\left(\mathrm{~mm}^{2}\right)$ & 572,26 & 530,66 & 530,66 \\
$\Sigma\left(\mathrm{kN} / \mathrm{mm}^{2}\right)$ & 7,67 & 8,67 & 10,46 \\
$\varepsilon(\%)$ & 0,22 & 0,22 & 0,22 \\
$\mathrm{E}(\mathrm{Pa})$ & 35,40 & 40,00 & 48,29 \\
\hline
\end{tabular}

Akibat suhu thermal yang lebih tinggi pada beban tekanan gesek 78,45 $N$ mengakibatkan tegangan tarik yang lebih tinggi dari beban tekanan gesek pada spesimen lain yaitu $10,46 \mathrm{kN} / \mathrm{mm}^{2}$, sedangkan modulus elastis juga memperlihatkan nilai tertinggi yaitu 48,29 $\mathrm{Pa}$ pada beban tekanan gesek $78,45 \mathrm{~N}$ seperti yang di perlihatkan pada Gambar 16.



Gambar 16. Grafik Hubungan Antara Beban Terhadap Tegangan dan Modulus Elastis

Dari Gambar 16 memperlihatkan bahwa semakin besar beban yang diberikan pada saat proses pengelasan gesek maka tegangan dan modulus elastis bahan juga semakin meningkat, pada saat beban 39,23 $N$ diperoleh tegangan terendah yaitu 7,67 $\mathrm{kN} / \mathrm{mm}^{2}$ dan pada saat beban 78,45 N tegangan tarik bahan yang diperoleh adalah 10,46 $\mathrm{kN} / \mathrm{mm}^{2}$, begitupun halnya dengan modulus elastis yang diperoleh untuk spesimen beban tekanan gesek 39,23 N sebesar 35,40 $\mathrm{Pa}$ dan untuk beban tekanan gesek 78,45 $\mathrm{N}$ adalah 48,29 $P a$. Hal tersebut menunjukkan bahwa apabila beban tekanan gesek kecil dalam proses pengelasan gesek dapat mengakibatkan kekuatan sambungan las gesek akan menjadi tidak baik, sedangkan pada saat beban tekanan gesek besar maka akan membuat sambungan las gesek akan lebih baik dan kuat karena beban tekanan gesek membantu proses penyambungan pada saat material dalam keadaan melumer akibat panas dari gesekan antara permukaan kedua material yang bergesekan sehingga beban tekanan gesek tersebut menjadi salah satu parameter penting dalam proses pengelasan gesek.

Dari hasil pengujian tarik dan perhitungan yang telah dilaksanakan diperoleh perubahan nilai regangan yang sangat kecil seperti yang disajikan dalam Gambar 17, tentang hubungan antara beban terhadap tegangan dan modulus elastis. Hal tersebut terjadi akibat dari hasil pengelasan gesek yang diperoleh belum maksimal.

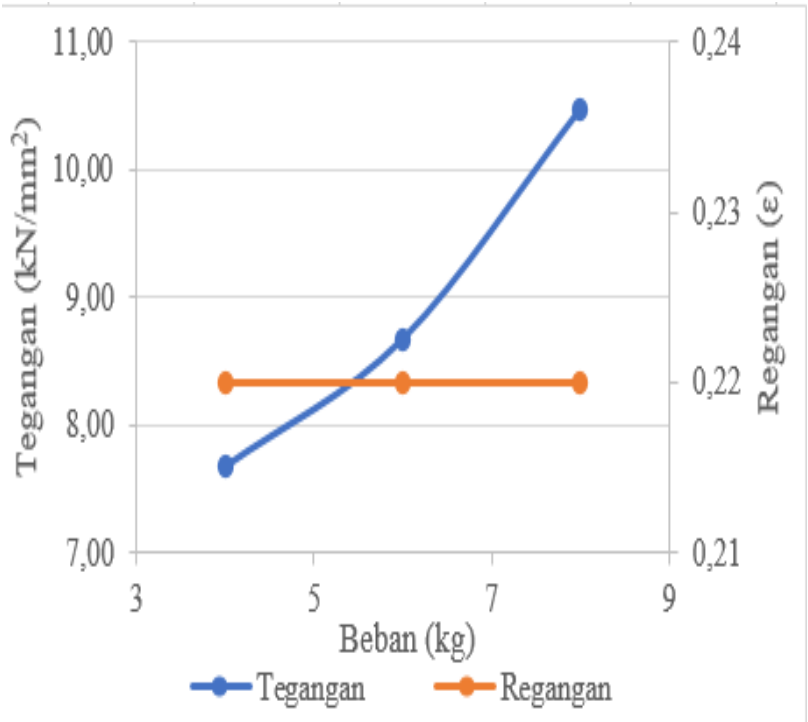

Gambar 17. Grafik Hubungan Antara Beban Terhadap Tegangan dan Regangan

Berdasarkan pengujian yang telah dilakukan, tegangan tarik pada spesimen baja karbon sedang setelah pengelasan gesek pada beban tekanan gesek 78,45 N lebih baik dari spesimen lain. Hasil pengujian diperlihatkan pada Gambar 17 menunjukkan tegangan tarik pada spesimen dengan beban tekanan gesek 78,45 N yaitu $10,46 \mathrm{kN} / \mathrm{mm}^{2}$ dan regangan yang diperoleh sebesar $0,22 \%$.

\section{KESIMPULAN}

Dari hasil penelitian yang telah dilaksanakan diperoleh beberapa hal yang menjadi kesimpulan sebagai berikut:

1. Semakin besar beban yang diberikan pada saat proses pengelasan gesek maka semakin besar pula tegangan tarik bahan (baja karbon sedang) dimana perbandingan yang terjadi adalah berbanding lurus seperti yang diperlihatkan dari hasil perhitungan. Tegangan tarik terendah diperoleh pada saat beban $39,23 \mathrm{~N}$ yaitu 7,67 $\mathrm{kN} / \mathrm{mm}^{2}$ sedangkan tegangan tarik terbesar diperoleh pada beban $78,45 N$ yaitu 10,46 $\mathrm{kN} / \mathrm{mm}^{2}$.

2. Dalam proses pengelasan gesek sangat penting untuk menjadi perhatian terhadap besarnya beban yang digunakan agar proses penyambungan material lebih solid dan akan memperoleh kekuatan sambungan las yang lebih baik karena beban yang diberikan pada saat pengelasan gesek sangat berpengaruh terhadap kekuatan tarik dari bahan tersebut. 


\section{UCAPAN TERIMA KASIH}

Ucapan terima kasih disampaikan kepada Politeknik Kotabaru khususnya Jurusan Teknik Mesin Politeknik Kotabaru yang telah memberikan dukungan dan fasilitas peralatan pada laboratorium dan Balai Latihan Kerja Industri (BLKI) Makassar sebagai tempat untuk melakukan pengujian tarik terhadap spesimen uji dalam penelitian ini.

\section{REFERENSI}

[1] H. W. Laksono and Sugiyanto, Analisa hasil Pengelasan gesek pada sambungan sama jenis baja ST 60, sama jenis AISI 201, dan beda jenis baja ST 60 dengan AISI 201, Jurnal Teknik Mesin S-1, vol. 2, no. 1, 2014, pp. 46-53.

[2] S. Prasetyono and H. Subiyanto, Pengaruh durasi gesek, tekanan gesek dan tekanan tempa terhadap impact strength sambungan lasan gesek langsung pada baja karbon AISI 1045, Jurnal Sains dan Seni Pomits, vol. 1, no. 1, 2012, pp. 1-5.

[3] A. Suhendar, Mawardi, and A. Ibrahim, Pengaruh durasi waktu pengelasan pada proses las gesek terhadap sifat mekanik material AISI 1045, Journal of Welding Technology, vol. 2, no. 2, 2020, pp. 45-50.

[4] Fitri., E. Ginting, and P. Karo karo, Komposisi Kimia, Struktur Mikro, Holding Time dan Sifat Ketangguhan Baja Karbon Medium pada Suhu $780{ }^{\circ} \mathrm{C}$, Jurnal Teori dan Aplikasi Fisika, vol. 01, no. 01, 2013, pp. 1-4.

[5] W. E. Nurfitriana, Material pesawat udara II dengan uji tarik komposit, Laporan, Politeknik Negeri Bandung, Bandung, 2016.

[6] Tiwan and A. Ardian, Penyambungan baja AISI 1040 batang silinder pejal dengan friction welding, Laporan, Universitas Negeri Yogyakarta, Yogyakarta, 2005.

[7] N. Husodo, E. Widiyono, M. Mursid, and P. Agista, Analisis Pengaruh tekanan tempa terhadap struktur mikro dan sifat mekanik stainless steel SS 304 dengan metode friction welding, Steman, vol. 6, no. 2, 2016 pp. 15-19.

[8] H. S. Raharjo and R. Jp, Variasi arus listrik terhadap sifat mekanis sambungan las shielding metal arc welding (SMAW), Simposium Nasional RAPI XI FT UMS, 2012, pp. 93-97.

[9] M. H. Sirait, Analisis peningkatan kekerasan bahan sproket dengan metode hardening pada penahanan waktu pemanasan, S.T. Skripsi, Universitas Medan Area, Medan, 2017.

[10] W. D. Callister and D. G. Rethwisch, Materials Science and Engineering An introduction (8nd edition), 8th ed. Amerika Serikat: Jonh Wiley \& Sons, Inc, 2009.

[11] R. Balaka, A. Kadir, and D. S. Tolantomo, Analisis pengaruh arus pengelasan pada sudut elektroda 70 terhadap sifat kekerasan dan struktur mikro baja karbon rendah menggunakan JIG welding, Enthalpy, vol. 2, no. 2, 2016, pp. 5055.

[12] Asrul, K. Kamil, and M. H. Asiri, Analisis kekuatan sambungan las metal inert gas (MIG) pada logam aluminium paduan AA6063 dengan variasi arus listrik, Teknik Mesin Teknologi, vol. 18, no. 1, 2018, pp. 27-32.

[13] E. K. Laksanawati and A. A. Gunawan, Pengujian kekuatan rig untuk uji tarik baja a36 diameter $30 \mathrm{~mm}$ bentuk standard dengan analisis software solidwork, Motor Bakar, vol. 2, no. 1, 2018, pp. 30-37.

[14] M. Faisal, M. Balfas, and K. Kamil, Analisis kekuatan tarik pada logam axle shaft dengan pengelasan gesek (friction welding), Teknik Mesin Teknologi, vol. 19, no. 1, 2018, pp. 25-30.

[15] T. Sugiarto, Zulhanif., and Sugiyanto, Analisis uji ketahanan lelah baja karbon sedang aisi 1045 dengan heat treatment (quenching) dengan menggunakan alat rotary bending, Jurnal Ilmu Teknik Mesin FEMA, vol. 1, no. 3, 2013, pp. 8592. 